\title{
Targeting gp130 aids cartilage repair
}

$\begin{array}{ll}\text { RCGD 423 } & \begin{array}{l}\text { IL-6 receptor subunit } \beta \text { (also } \\ \text { known as gp130) has a vital role in } \\ \text { initiating signalling through the } \\ \text { reduced }\end{array} \\ \begin{array}{l}\text { IL-6 receptor (IL-6R), a pathway } \\ \text { thought to mediate the low-grade } \\ \text { inflammation associated with } \\ \text { degradation, } \\ \text { osteoarthritis (OA). Following an } \\ \text { extensive search, researchers have } \\ \text { damage and }\end{array} & \begin{array}{l}\text { now identified a regulator of gp130 } \\ \text { that can reduce cartilage damage } \\ \text { and promote cartilage repair in }\end{array} \\ \text { of osteophytes } & \begin{array}{l}\text { rodent models of OA. } \\ \text { "Our data demonstrate that not } \\ \text { all signalling downstream of IL-6 } \\ \text { family cytokines is detrimental and } \\ \text { highlight a new class of small mol- } \\ \text { ecules with anti-inflammatory and } \\ \text { pro-regenerative effects that could }\end{array}\end{array}$
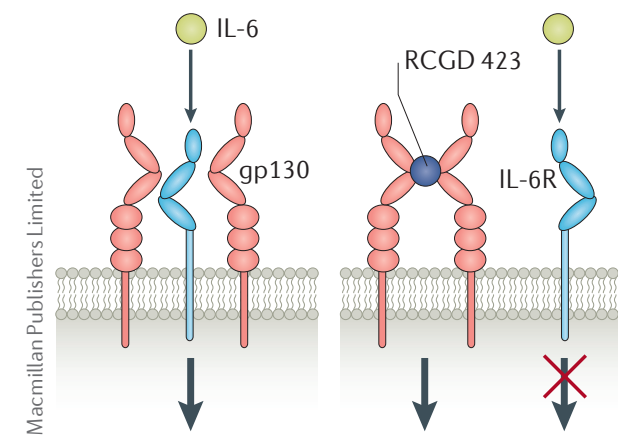

be the basis for future therapeutic candidates," states corresponding author Denis Evseenko.

The novel small-molecule modulator RCGD 423 acts by binding to domain 2 of gp130 and causing homodimerization, thereby reducing the number of gp 130 molecules available to dimerize with IL-6 family cytokine receptors. This reduction in the bioavailability of gp130 alters mitogen-activated protein kinase (MAPK) and signal transducer and activator of transcription (STAT) signalling cascades.

"Signalling mediated by IL-6 family cytokines is both contextdependent and ligand-dependent," explains Evseenko. "Specifically, some ligands such as oncostatin M strongly promote MAPK-nuclear factor- $\kappa \mathrm{B}(\mathrm{NF}-\kappa \mathrm{B})$ activity while promoting comparatively little STAT3 activation, whereas others such as LIF and IL- 6 result in activation of both pathways." Uniquely, compared with natural ligands, RCGD 423 not only reduced signalling via pro-inflammatory MAPK-NF- $\kappa B$ pathways, but also promoted signalling via pro-regenerative phosphorylated STAT3-proto-oncogene
MYC pathways in adult human articular chondrocytes.

Placing this compound into a disease scenario, Evseenko and colleagues showed that RCGD 423 could attenuate hypertrophy in vitro in articular chondrocytes from patients with OA. When administered intra-articularly in a rat model of OA (destabilization of the medial meniscus), RCGD 423 reduced cartilage degradation, structural damage and the generation of osteophytes compared with vehicle-treated animals. In a further rat osteochondral defect model, in which cartilage defects spontaneously repair after 4 weeks, RCGD 423 aided cartilage regeneration compared with vehicle.

"We are just at the beginning of understanding the implications and development potential of this work," says Evseenko. "In addition to OA we are actively pursuing the use of these molecules for other inflammatory conditions."

Joanna Collison

ORIGINAL ARTICLE Shkhyan, R. et al. Drug-induced modulation of gp130 signalling prevents articular cartilage degeneration and promotes repair. Ann. Rheum. Dis. https://doi. org/10.1136/annrheumdis-2017-212037 (2018) 